\title{
Is There Any Need for the Concept of Directional Syncretism?
}

\author{
Dieter Wunderlich*
}

\section{Introduction: The Typology of Syncretism by Stump (2001)}

Stump (2001) distinguishes four types of syncretism, according to how they should be analyzed best.

- unidirectional syncretism,

- bidirectional syncretism,

- unstipulated syncretism,

- symmetrical syncretism.

Stump favors the concept of directional syncretism because it can be formalized by a grammatical rule that operates on paradigms, a so-called rule of referral. This syncretism is termed "directional" because the rule maps the entry of one cell of the paradigm to another. Which cell is the target of the rule is motivated by independent reasons. In most Indo-European languages, the nominative and accusative forms of neuter nouns are identical (Greek to: do:ron ('the gift'), Latin do:num ('gift'), Russian slovo ('word'), German das Schiff ('the ship')). It is reasonable to assume that accusative is the marked context in these pairs, so that the rule of referral can be expressed as in (1).

(1) $\mathrm{N} \rightarrow \mathrm{A}$, for neuter nouns

Neuter nouns with this property thus exhibit the unidirectional type. In section 4, I will discuss a syncretism between genitive singular and nominative plural in Russian nouns, which Stump analyzes by the rule G.sg $\rightarrow$ N.pl in

\footnotetext{
${ }^{*}$ The research for this paper was supported by SFB 282, Theorie des Lexikons, sponsored by the DFG. Parts of the paper were presented at a conference dedicated to the memory of Wolfgang Ullrich Wurzel at ZAS Berlin (Zentrum für Allgemeine Sprachwissenschaft). I am grateful for the comments by Albert Ortmann and Gereon Müller.
}

Explorations in Nominal Inflection, 373-395

Gereon Müller, Lutz Gunkel, \& Gisela Zifonun (eds.)

Copyright (c) 2004, Mouton de Gruyter, Berlin 
some instances, and by the rule N.pl $\rightarrow$ G.sg in other instances. This type of syncretism is called "bidirectional". The third type of syncretism, unstipulated syncretism, is found where the syncretism matches with a natural class. It is the least controversial type and can be captured by lexical underspecification. For instance, the genitive and the dative forms of masculine and neuter nominal elements in German (other than the noun itself) are identical (des Affen, dem Affen (masc.) ('of/to the ape'), des Schafes, dem Schaf (neut.) ('of/to the sheep')). Here, non-feminine is a natural class that subsumes both masculine and neuter (des G.sg.-fem, dem D.sg.-fem).

For reasons that are unclear to me, Stump disfavors the possibility of underspecification. Many of the instances that are analyzed by Stump as directional syncretism can be given an alternative analysis in terms of underspecification. ${ }^{1}$ In my view, such an analysis is the most desirable because it reduces paradigmatic space. In German verb inflection, first person and third person forms are always alike, except in the present indicative singular (ich/sie lachte ('I/she laughed'), wir/sie schliefen ('we/they slept')). These forms can be analyzed by referring to the natural class non-second person (= "not the addressee").

The last type of syncretism is symmetrical syncretism. It is subject neither to underspecification nor to any systematic relationship between categories. This type is a residual case for Stump. It includes idiosyncratic ('accidental') syncretism, as in the article system of German, where the forms of N.sg masc, G./D.sg fem, and G.pl are identical (der Mann ('the man'), der Frau ('of/to the woman'), der Männer ('of the men')), and no plausible relationship is recognizable. ${ }^{2}$ More interestingly, it also includes a few rather systematic homonymies. One intriguing case cited by Stump is Hua (New Guinea, Haiman (1980)), a language in which verbs inflected for 2 sg and $1 \mathrm{pl}$ always have identical forms, regardless of how they are realized in the

\footnotetext{
${ }^{1}$ In Wunderlich (1996), I reanalyzed Stump's (1993) account concerning the verbal paradigms of Macedonian. In the same spirit, I reanalyzed the referral analysis of the prenominal prefixes in Dalabon verbs by Evans et al. (2001) in Wunderlich (2001).

${ }^{2}$ Müller (2002) presents an analysis of the nominal inflection in German in which the syncretism just mentioned follows from phono-morphological iconicity: The less marked a suffix is in terms of the Sonority Hierarchy, the less marked is the set of categories that can be expressed by this suffix. /-e/ is optimal according to the Sonority Hierarchy, and is chosen for [-masc,-obl] categories, while /-r/ is next-to-optimal and is chosen for categories other than [-masc,-obl]. Note that this proposal crucially hinges on a choice of categories that is not commonly accepted: [-masc] comprises feminines and plurals, and [-obl] comprises nominative and accusative.
} 
various moods. Stump proposes dealing with this fact by means of a metageneralization. Unlike a grammatical rule, a meta-generalization restricts the possible lexical entries, so I would like to argue.

While I believe this latter type to be sufficiently justified, I have serious doubts whether directional syncretism is an adequate concept. A learner who is assumed to acquire a rule of referral would first have to acquire the exponents of quite different paradigmatic cells. Particularly problematic is the fact that the learner not only has to identify identical forms (which amounts to saying that he or she already knows the syncretism) but, moreover, would have to find out which form triggers which. Obviously, the type that is the hardest to acquire is bidirectional syncretism. Of course, a statement that a bidirectional syncretism exists is a stronger claim than a statement that a symmetric syncretism exists. Methodologically, however, the best hypothesis for a grammar is not the one that makes the strongest generalizations, but rather one that makes the most plausible generalizations. My claim is that rules of referral are undesirable for theoretical reasons.

As I will show in this paper on the basis of case studies, the notion of rules of referral is equally unnecessary. All examples of supposed directional syncretism, i.e., either unidirectional or bidirectional, represent either unstipulated or symmetrical syncretism. That is, every kind of syncretism is best captured in the lexical entries for affixes, provided one assumes a set of violable (and therefore ranked) constraints that regulate the choice between inflected forms. In the next section, I will show that the above-mentioned A/N syncretism of neuter NPs in Indo-European is most naturally captured by underspecification. In section 3, I discuss another syncretism occurring in Russian nouns, which is subject to animacy. The accusative of inanimate nouns often shares its form with the nominative, while the accusative of animate nouns shares its form with the genitive. This syncretism split, again, has been described as directional. I will show that it can be captured by the interaction of lexical entries with well-motivated constraints. In section 4, I discuss an example that Stump analyzes as an instance of bidirectional syncretism, namely the G.sg/N.pl syncretism of Russian nouns, which does not involve a natural class. This syncretism is not specific to Russian, but rather is of Indo-European nature and is best captured as symmetrical.

The overall aim of the paper, then, is to show that Stump's typology at a closer look reduces to his third and fourth class, which is also desirable 
considering that we ought to establish a typology that is guided by features of the grammar rather than by features of analyzability.

\section{The A/N Syncretism of Indo-European Neuter Nouns}

As noted above, many Indo-European languages identify the accusative of neuter nouns (or neuter NPs) with the nominative. This fact finds its most natural account in the assumption that the accusative is a marked case with respect to the nominative. To implement this intuition, accusative is specified by the feature $[+\mathrm{hr}]$ "there is a higher role", whereas nominative bears no such feature (Wunderlich (1997)). The syncretism, then, follows from the fact that the accusative of neuters is left unspecified, i.e., a special accusative form of neuters is lacking, so that the nominative form can (and must) cover both nominative and accusative contexts. Never do we find a more marked form, e.g., dative, that is tolerated in such a context. Note that an accusative context arises, for example, from the requirement for a transitive verb to take an accusative complement, as well as from the requirement for a predicative noun to show case concord with its subject, when this is itself in an accusative context.

Beekes $(1995,193 \mathrm{f}$.$) gives the following historical explanation for the$ lack of accusative in Indo-European neuter nouns. He assumes that IndoEuropean was formerly a language with an ergative split, where the ergative was restricted to masculine or feminine animate nouns, while neuter inanimate nouns exhibited "absolutive" (i.e., nominative) for both subject and object of transitive verbs. ${ }^{3}$ Indo-European subsequently shifted to an accusative pattern in which the syncretism remained.

This explanation is, however, doubtful in view of universal tendencies. Universally, a gap in the ergative is more likely for animates than for inanimates, while a gap in the accusative is more likely for inanimates. This is also predicted by the framework of harmonic alignment within OT (Aissen (1999), Stiebels (2000)). If one wants to account for the situation where the realization of case is determined by values of animacy, the morphological scale in (2-a) (Stiebels $(2000,237))$ and the semantic scale in (2-b) represent the relevant pieces of information to start from. (Note that ergative is specified

\footnotetext{
${ }^{3}$ A similar hypothesis is discussed by Schmitt-Brandt $(1998,190)$, who states that neuter nouns failed to have ergative endings because they are only rarely used as the subject of transitive verbs. This commentary reduces the lack of ergative to a matter of statistics.
} 
by [+lr], "there is a lower role".) Considering the semantic values as possible contexts of the morphological values, the two scales have to be aligned. By harmonic alignment, the markedness rankings in (3-a) and (3-b) arise.

(2) a. $[+\mathrm{hr}]>[+\mathrm{lr}]$

'Marking a lower argument is preferred over marking a higher one.'

b. anim > inanim

(3) a. $*[+\operatorname{lr}] /$ anim $\gg *[+\operatorname{lr}] /$ inanim

'Avoiding ergative for animates is better than avoiding it for inanimates.'

b. $*[+\mathrm{hr}] /$ inanim $\gg *[+\mathrm{hr}] /$ anim

'Avoiding accusative for inanimates is better than avoiding it for animates.'

This suggests that the $\mathrm{A} / \mathrm{N}$ syncretism of neuter nouns in Indo-European can in fact be traced to the fact that neuter nouns are most likely to express inanimate concepts. Such a semantic background can be subject to grammaticalization, so that the semantic scale in (2-b) has to be replaced by the gender scale in (4-a), and, accordingly, the markedness ranking in (3-b) by that in (4-b). For completeness, the situation in Indo-European is fully captured if in addition one assumes that the constraint $\operatorname{MAX}(+\mathrm{hr})$, 'Realize the feature [+hr] (by accusative)', is interpolated as in (4-c).

(4) a. non-neuter $>$ neuter

b. $*[+\mathrm{hr}] /$ neuter $\gg *[+\mathrm{hr}] /$ non-neuter

'Avoiding accusative for neuters is better than avoiding it for nonneuters.'

c. $*[+h r] /$ neuter $\gg \operatorname{MAX}(+h r) \gg *[+h r] /$ non-neuter

As regards the explanation given by Beekes, the rankings given in (3-a) and (3-b) suggest that either Indo-European never had an ergative system, or that the A/N syncretism evolved only when the system had already shifted to accusativity. It could also be the case that for some other reason a syncretism evolved within an ergative system, which then might have been one of the triggering factors for the shift into an accusative system.

In any case, if a dominant constraint such as *[+hr]/neuter is derived as a grammaticalized instance of the universally motivated constraint *[+hr]/inanim, one arrives at a much better explanation for the $\mathrm{A} / \mathrm{N}$ syncretism than by a stipulated rule of referral. 
Note in this connection that German feminine and plural nominal forms are subject to the $\mathrm{A} / \mathrm{N}$ syncretism, too. In light of the preceding discussion, these syncretisms should also be captured by markedness constraints. The semantic scale assumed in (2-b), namely, anim > inanim, can be extended as in (5-a), which gives rise to the markedness ranking in (5-b).

(5) a. male $>$ female $>$ group $>$ inanim

b. $*[+\mathrm{hr}] /$ inanim $\gg *[+\mathrm{hr}] /$ group $\gg *[+\mathrm{hr}] /$ female $\gg *[+\mathrm{hr}] /$ male

The ranking male $>$ female is motivated by the dominant role of men in certain societies, with the effect that agentivity is taken to be more prototypical of males, and individual $>$ group is motivated by specificity. This semantic background, then, has been grammaticalized by means of gender and number. Eventually, MAX(+hr) intervenes between the third and fourth constraint, so that only masculine accusatives remain.

(6) a. *[+hr]/neuter $\gg *[+\mathrm{hr}] /$ plural $\gg *[+\mathrm{hr}] /$ fem. $\gg \operatorname{MAX}(+\mathrm{hr}) \gg$ $*[+\mathrm{hr}] /$ masc.

b. $*[+\mathrm{hr}] /$ non-masc. $\vee$ plural $\gg \operatorname{MAX}(+\mathrm{hr}) \gg *[+\mathrm{hr}] /$ masc.

(6-b) summarizes the three Avoid constraints of (6-a) in just one context. Again, such an account seems better motivated than (a template for) rules of referral.

\section{Syncretism and Animacy Split in the Russian Accusative}

It is a well-known fact that the Russian accusative is defective; all nouns other than class 2 in the singular, ${ }^{4}$ as well as all nouns in the plural, lack

\footnotetext{
${ }^{4}$ The terms "class 1", "class 2", "class 3" are used here for the sake of simplicity. Differing from authors such as Corbett (1982; 1991) and Stump (2001), I do not believe that nouns bear an uninterpretable class feature. Instead, the class they belong to can be identified by gender and phonological features. For small and unproductive classes, all specific forms of the noun are presumably listed in the lexicon. Here, then, one often finds additional syncretism, e.g., between genitive and dative singular.

Traditionally, class 1 comprises masculine and neuter nouns, the former always ending in a consonant and the latter in $-o$ or $-e$ in N.sg; the respective stems can also end in /-j/ or a palatalized consonant, which trigger allomorphs. Here, I separate the neuter nouns as a distinct class 4 . Class 2 stems always end in - $a$ in N.sg while class 3 stems always end in a palatalized consonant; items of these two classes are mostly feminine. Note that [i] is an allophone of /-y/ after a palatal (or palatalized) consonant; likewise, [e] is an allomorph of /-o/ in such an environment.
} 
a separate accusative affix, and instead share either the nominative or the genitive form in a context that requires accusative. This split is traditionally described by two instances of rules of referral, and accordingly analyzed by authors such as Corbett $(1982 ; 1991)$ and Stump (2001). One can see from (7) that there is only one genuine accusative form in Russian, namely /-u/ for class 2 nouns ending in /-a/. Note that all neuter nouns automatically pattern with the inanimates because of the general $\mathrm{A} / \mathrm{N}$ syncretism found in neuters. The explanation given for this syncretism in section 2 suggests a similar account for the left side of (7), involving inanimates.

(7) Russian nouns with animacy split in forms that are used in accusative contexts

\begin{tabular}{|c||c|c|c|c|c|c|c|}
\hline \multicolumn{1}{|c||}{} & \multicolumn{4}{c|}{ inanimates } & \multicolumn{3}{c|}{ animates } \\
\cline { 2 - 7 } & class 2 & class 3 & class 1 & class 4 & class 2 & class 3 & class 1 \\
\hline & fem. & fem. & masc. & neut. & fem. & fem. & masc. \\
& 'map' & 'door' & 'table' & 'word' & 'squirrel' & 'mother' & 'student' \\
\hline N.sg. & kárt-a & dver' & stol & slov-o & bélk-a & mat' & studént \\
A.sg. & kárt-u & dver' & stol & slov-o & bélk-u & mat' & studént-a \\
G.sg. & kárt-y & dvér-i & stol-á & slov-á & bélk-i & máter-i & studént-a \\
\hline N.pl. & kárt-y & dvér-i & stol-ýy & slov-á & bélk-i & máter-i & studént-y \\
A.pl. & kárt-y & dvér-i & stol-ý & slov-á & bélok & máter-ej & studént-ov \\
G.pl. & kart & dver-éj & stol-óv & slov & bélok & máter-ej & studént-ov \\
\hline
\end{tabular}

The empirical generalization is the following: All class 2 nouns (ending in /-a//) have the ending /-u/ in the A.sg. Otherwise, the accusative of inanimate nouns patterns with nominative (hence $\mathrm{N} \rightarrow \mathrm{A}$ ), and the accusative of animate nouns patterns with genitive (hence $\mathrm{G} \rightarrow \mathrm{A}$ ), except in class 3 (nouns ending in a palatalized consonant), where A.sg always patterns with nominative, regardless of animacy.

The alternative account I propose extends the solution for the A/N syncretism given in section 2 by the assumption that the A/G syncretism forms a natural class and should therefore be characterized by lexical underspecification. The choice between the two options, namely between an $\mathrm{A} / \mathrm{N}$ or an A/G syncretism, is partially restricted by the lexical information itself, more specifically, by the final segment of the underlying stem (in class 2 nouns, and the singular of "animate" class 3 nouns); otherwise it is made by the constraint ranking. 
In section 2, I analyzed nominative as the unspecified case, which can enter any context, provided that more specific realizations (such as accusative) are blocked. A/N syncretism arises when only the nominative form can enter an accusative context.

In contrast, in the $\mathrm{A} / \mathrm{G}$ syncretism neither of the two cases can be considered to be more specific than the other. Rather, there is one feature that is shared by these two cases, and another feature that distinguishes them, here noted as a subscript: Genitive (both the case morphemes and the relevant contexts) ${ }^{5}$ is specified by the feature $(+h r)_{N}$ "there is a higher role" (of nouns), while accusative (both the case morphemes and the relevant contexts) is specified by the feature $(+\mathrm{hr})_{V}$ "there is a higher role" (of verbs). Therefore, the A/G syncretism can be captured by lexical entries which are simply specified as (+hr); that is, they are underspecified with respect to $\mathrm{V}$ or $\mathrm{N}$.

Disregarding neuter nouns with the plural in $/-\mathrm{a} /$, there is only one unrestricted plural suffix, namely, /-y/, to be realized as [y] or [i], depending on the phonological environment. Thus, forms with this suffix can potentially enter accusative contexts as well as any singular form.

As already mentioned, /-u/ is a genuine accusative suffix that is restricted to class 2 nouns, a fact that is expressed by the context "a]". Note that the stem-final $-a$ is a thematic or floating vowel, which appears only if no other vowel is specified. Thus, the accusative is realized by the suffix $-u$, while the nominative (with no suffix) receives the ending $-a$. Similarly, neuter nouns (class 4) have the thematic vowel $-0 .{ }^{6}$

The other genuine case suffix is genitive /-y/. It occurs with all class 2 and class 3 nouns, that is, nouns ending either with thematic $-a$ or with the palatal feature PAL. Forms that are generated with this suffix can never be generalized to accusative. Thus, regardless of whether a PAL ending noun is animate or inanimate, a special accusative form is lacking, and it is only the nominative form that can generalize to accusative contexts, specified as $(+\mathrm{hr})_{V}$.

All other suffixes relevant here are subject to the A/G syncretism. They realize the feature $[+\mathrm{hr}]$, without any specification for a nominal or verbal

\footnotetext{
${ }^{5} \mathrm{~A}$ potential genitive context is also found with verbs in the scope of negation. In this instance, the subject or object role of a verb is exceptionally marked $(+\mathrm{hr})_{N}$.

${ }^{6}$ Although the thematic vowel in fact appears only in the nominative, it is not considered to be a nominative affix. Because of the dominance of nominative contexts, children can easily identify the nominative form from the very beginning and thus become aware of the fact that some nouns end in $-a$ or $-o$, while other nouns end in $\mathrm{C}$.
} 
context. The ending /-a/ is a (singular) suffix for class 1 nouns (the default class), as well as for class 4 nouns. Thus, class 1 nouns ending in - $a$ can enter either genitive or accusative contexts, depending on a further condition which captures the animacy split, while the inanimate neuter nouns of class 4 can enter only genitive contexts.

Similarly, all the remaining plural suffixes realize the feature combination $[+\mathrm{hr},+\mathrm{pl}]$, without any specification for a nominal or verbal context: the zero ending in class 2 and class 4 nouns, ${ }^{7}$ the $-e j$ ending in class 3 nouns, and the -ov ending in class 1 nouns. All these forms can enter both genitive and accusative contexts.

The set of suffixes just discussed is given in (8). ${ }^{8}$

(8) Suffixes
a. $\mid-\mathrm{y} /,+\mathrm{pl}$
b. $/-\mathrm{a} /,+\mathrm{pl} /$ neuter
c. $\left./-\mathrm{u} /,(+\mathrm{hr})_{V} / \mathrm{a}\right]$
d. $\left.\left./-\mathrm{y} /,(+\mathrm{hr})_{N} / \mathrm{a}\right] \vee \mathrm{PAL}\right]$
e. $/-\mathrm{a} /,+\mathrm{hr} / \mathrm{C}] \vee \mathrm{o}]$
f. C], $+\mathrm{pl},+\mathrm{hr} / \mathrm{a}] \vee \mathrm{o}]$
g. /-ej/, +pl,+hr / PAL]
h. $/-\mathrm{ov} /,+\mathrm{pl},+\mathrm{hr}$

N.pl (class 1,2 \& 3)

N.pl (class 4)

A.sg (class 2)

G.sg (class 2 \& 3)

A/G.sg (class 1 \& 4)

A/G.pl (class $2 \& 4)$

A/G.pl (class 3)

A/G.pl (class 1)

For convenience, the interplay of the lexical entries of suffixes is illustrated by the paradigm they form in (9). Note that there is no affix that refers to animacy.

\footnotetext{
${ }^{7}$ More specifically, I assume that the zero ending results from a condition that the respective form ends in $\mathrm{C}$, which is best realized by the stem-final consonantal segment, so that the thematic (floating) vowel /-a/ or /-o/ is not realized. This can be regulated by the requirement that the addition of consonantal features is more costly than the drop of vocalic features. (If the resulting form ends with a consonant cluster, often an epenthetic vowel is inserted, as in N.sg kúkla-G.pl kúkol ('puppet'), which is obviously less costly than the addition of consonantal features.) Thus, C] is not a true suffix but rather a condition for (A)/G.pl forms. Particularly interesting is the fact that, deviating from the general pattern, nouns with a monosyllabic palatalized stem and /-a/ or /-o/ in the N.sg take the G.pl ending /ej/ of palatalized stems rather than zero if they have to bear final stress in the plural (N.sg dól'a-G.pl doléj ('portion'), N.sg móre - G.pl moréj ('sea')). In these instances, the condition of final stress can be satisfied only if a true affix is added. All these facts strongly suggest an OT-analysis of Russian G.pl forms. (See also the analysis by Brown and Hippisley (1994) in the DATR framework.)

${ }^{8}$ It is not necessary to specify all the selectional contexts; at least one of the suffixes specified as [+hr] could function as a default, similarly to /-ov/ in the set of suffixes specified as $[+\mathrm{pl},+\mathrm{hr}]$. See the discussion below.
} 
(9) Lexical entries for some Russian case affixes

\begin{tabular}{|c|c|c|c|c|c|c|}
\hline & \multicolumn{3}{|c|}{ inanimates } & \multicolumn{3}{|c|}{ animates } \\
\hline & $\begin{array}{l}\text { class } 2 \\
\end{array}$ & class 3 & class 1 & class 2 & class 3 & class 1 \\
\hline & 'map' & 'door' & 'table' & 'squirrel' & 'mother' & 'student' \\
\hline \multirow{3}{*}{$\begin{array}{l}\text { N.sg. } \\
\text { A.sg. } \\
\text { G.sg. }\end{array}$} & a] & \multirow[t]{2}{*}{ PAL] } & & a] & \multirow[t]{2}{*}{ PAL] } & \\
\hline & $/-\mathrm{u} /,(+\mathrm{hr})_{V}$ & & & /-u/, $(+\mathrm{hr})_{V}$ & & \multirow[b]{2}{*}{ /-a/, +hr } \\
\hline & /-y/, $(+$ & ir $)_{N}$ & $/-\mathrm{a} /,+\mathrm{hr}$ & /-y/, (+ & $\mathrm{hr})_{N}$ & \\
\hline \multirow{2}{*}{$\begin{array}{l}\text { N.pl. } \\
\text { A.pl. } \\
\text { G.pl. }\end{array}$} & \multicolumn{3}{|c|}{ /-y/, $+\mathrm{pl}$} & \multicolumn{3}{|c|}{ /-y/, +pl } \\
\hline & $\begin{array}{c}\mathrm{Cl}, \\
+\mathrm{pl},+\mathrm{hr}\end{array}$ & $\begin{array}{c}\text { /ej/, } \\
+ \text { +pl, }+ \text { hr }\end{array}$ & $\begin{array}{c}\begin{array}{c}\text { /ov/, } \\
+\mathrm{pl},+\mathrm{hr}\end{array} \\
\end{array}$ & $\begin{array}{c}\mathrm{C}], \\
+\mathrm{pl},+\mathrm{hr}\end{array}$ & $\begin{array}{c}\begin{array}{c}\text { /ej/, } \\
+\mathrm{pl},+\mathrm{hr}\end{array}\end{array}$ & $\begin{array}{c}\text { /ov/, } \\
+\mathrm{pl},+\mathrm{hr}\end{array}$ \\
\hline
\end{tabular}

The animacy split was already motivated in section 2. I have argued that the A/N syncretism observed in Indo-European neuter nouns follows from a grammaticalization of the context in a universally high-ranked constraint, namely, $*(+\mathrm{hr}) /$ inanim, resulting in the constraint $*(+\mathrm{hr}) /$ neuter. In the development of Russian, this latter constraint has obviously been retraced to its semantic source, so that the semantic constraint is reactivated. More precisely, since we are dealing with a lack of accusative rather than of genitive forms, the relevant constraint is to be read as in (10-a). As observed above, the realization of genitive is never blocked. Rather, in the plural the genitive is generalized so as to express simply $[+\mathrm{pl},+\mathrm{hr}]$, so that it can also occupy accusative contexts in cases where the realization of $[+\mathrm{hr}]$ is not blocked. Therefore, the intervening faithfulness constraint is simply MAX $(+\mathrm{hr})$, regardless of whether $[+\mathrm{hr}]$ is determined in a nominal or verbal context. We thus arrive at the constraint ranking stated in (10-c).

(10) Constraints

a. $*(+\mathrm{hr}) /_{V}$ inanim. Do not realize the feature $[+\mathrm{hr}]$ in accusative contexts of inanimate nouns. ${ }^{9}$

b. $\operatorname{MAX}(+h r)$. Realize the feature $[+h r]$.

c. Ranking of the constraints: $*(+\mathrm{hr}) /_{V}$ inanim $\gg \operatorname{MAX}(+\mathrm{hr}) \gg *(+\mathrm{hr}) /_{V}$ anim

\footnotetext{
${ }^{9}$ Russian has a few animate nouns in the neuter class 4 (such as čudovišče ('monster')), which nevertheless show A/N syncretism. If we assume that the Indo-European constraint against neuter accusative is still valid, any A/G syncretism is blocked. Therefore, the actual constraint is $*(+h r) /_{V}$ inanim $\vee$ neuter.
} 
Note that the ranking in (10-c) determines both the minimal inventory of affixes and the actual use of affixes, with the sole exception of inanimate class 2 nouns, which end in /-a/. (10-c) implies that inanimates should never have a separate accusative form, that a genitive form is always allowed, and that genitives are as good as separate accusative forms for animate nouns. Hence, for reasons of economy, separate accusative forms for animate nouns need not, and therefore may not, be established. This explains the A/G syncretism observed for animate nouns.

The analysis so far is still left with a problem. The constraint ranking in (10-c) predicts an $\mathrm{A} / \mathrm{N}$ syncretism for inanimate karta ('map'); that is, the form karta rather than kartu should be used in accusative contexts. Technically, such a prediction can be blocked by a higher-ranked constraint that requires faithfulness to [+hr] in the singular of class 2 nouns:

(11) $\operatorname{MAX}(+\mathrm{hr}) /-\mathrm{pl}, \mathrm{a}]$

Such a constraint could be motivated by the pressure to keep the accusative form of nouns referring to females (class 2 nouns, which end in $-a$ in the nominative) distinct from the accusative form of nouns referring to males (class 1 nouns), as well as from the genitive form of class 1 and class 4 nouns, both of which also end in $-a$. As a result, all class 2 nouns behave similarly because of the requirement of paradigmatic uniformity.

For the sake of illustrating the selection of optimal forms, let us assume that all affixes need the selectional specifications given in (8), and that no affix is applied if such a specification is not met. However, in some instances there is a choice. Therefore, further inviolable constraints are needed because certain combinations of stem and affix should be avoided and the generated forms should fail in a context where the categorial specifications conflict with each other. In particular, the features $\mathrm{V}$ and $\mathrm{N}$ are incompatible.

(12) a. SPECIFICITY

Choose the affix with the more specific selectional information. ${ }^{10}$

b. Compatibility

Do not insert a form in a context in which the categorial specifications are incompatible.

The ordering of these constraints is summarized in (13).

${ }^{10}$ This type of specificity is called input specificity by Wunderlich \& Fabri (1995). 


\section{(13) Ranking of the constraints}

SPEC, COMP, MAX $(+\mathrm{hr}) /-\mathrm{pl}, \mathrm{a}] \gg *(+\mathrm{hr}) / V_{V}-$ anim $\gg \operatorname{MAX}(+\mathrm{hr})$

Put into words: "Realize both accusative and genitive, unless inanimate nouns occur in accusative contexts, excluding class 2 nouns (ending in $-a$, where there exists the accusative morpheme /-u/)."

The following tableaux show the selection of the optimal singular form in accusative contexts, characterized by $[+\mathrm{hr}]_{V}$. Forms ending in /-y/ are blocked by COMP because they are specified as $[+\mathrm{hr}]_{N}$; SPEC does not have any function here, because the selectional contexts of the suffixes are fully specified; there is no default suffix assumed, in contrast to the plural.

(14) Selection of optimal forms in an accusative singular context

a. Inanimate class 2 nouns ( a] )

\begin{tabular}{|c|c|c|c|c|}
\hline & SPEC, COMP & $\begin{array}{c}\mathrm{MAX}(+\mathrm{hr}) / \\
-\mathrm{pl}, \mathrm{a}]\end{array}$ & $\begin{array}{c}*(+\mathrm{hr}) / V \\
\text {-anim }\end{array}$ & MAX(+hr) \\
\hline karta & 1 & I $\quad * !$ & & * \\
\hline kart-y & ! $*$ & $\frac{T}{1}$ & & \\
\hline 䟚 kart-u & I & $I$ & & \\
\hline
\end{tabular}

b. Inanimate class 1 nouns (masc)

\begin{tabular}{|c|c|c|c|}
\hline & $\begin{array}{c:c:c}\text { SPEC COMP , } & \text { MAX }(+h r) / \\
& & -p l, a]\end{array}$ & $\begin{array}{l}*(+\mathrm{hr}) / V \\
-\operatorname{anim}\end{array}$ & MAX $(+h r)$ \\
\hline stol & I & & $*$ \\
\hline stol-a & $T$ & $* !$ & \\
\hline stol-y & I $\quad * !$ & & \\
\hline
\end{tabular}

c. Animate class 1 nouns (masc)

\begin{tabular}{|c|c|c|c|}
\hline & $\begin{array}{c:c}\text { SPEC , COMP } & \operatorname{MAX}(+\mathrm{hr}) / \\
& -\mathrm{pl}, \mathrm{a}]\end{array}$ & $\begin{array}{l}*(+\mathrm{hr}) / V \\
-\operatorname{anim}\end{array}$ & $\operatorname{MAX}(+h r)$ \\
\hline student & 1 & & $* !$ \\
\hline student-a & 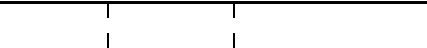 & & \\
\hline student-y & I $\quad * !$ & & \\
\hline
\end{tabular}

d. Animate class 3 nouns ( PAL])

\begin{tabular}{|c|c|c|c|c|}
\hline & $\begin{array}{c}\text { SPEC , COMP } \\
\text {, }\end{array}$ & $\begin{array}{c}\text { MAX }(+h r) / \\
-p l, a]\end{array}$ & $\begin{array}{l}*(+\mathrm{hr}) / V \\
\text {-anim }\end{array}$ & $\operatorname{MAX}(+h r)$ \\
\hline mat' & 1 & 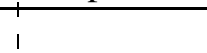 & & $*$ \\
\hline mater'-i & $* !$ & 1 & & \\
\hline
\end{tabular}


As already stated in the foregoing discussion, the A/N.sg syncretism of karta is blocked by the higher-ranked contextualized MAX-constraint. The A/N.sg syncretism of stol follows from the fact that stol is inanimate. The A/N.sg syncretism of mat' follows from the fact that the only available class 3 affix $/-y /$ is restricted to genitive. Finally, the A/G.sg syncretism of student follows from the fact that student is animate, and $/-\mathrm{a} /$ is an unrestricted (+hr)-affix.

As a means of summarizing the discussion, I list the sources for the appearance or blocking of syncretisms in (15). Thus, all syncretism turns out to be an epiphenomenon.

(15) $A / N$ and $A / G$ syncretisms in Russian nouns

\begin{tabular}{|l|l|l|l|}
\hline \multicolumn{2}{|c|}{ A/N syncretism } & \multicolumn{2}{c|}{ A/G syncretism } \\
appears because & is blocked because & appears because & is blocked because \\
\hline $\begin{array}{l}\text { no affix is } \\
\text { available (class 3) }\end{array}$ & $\begin{array}{l}\text { an affix is } \\
\text { available (class 2) }\end{array}$ & $\begin{array}{l}\text { only underspec- } \\
\text { ified affixes are } \\
\text { available (class } \\
1 \text { and plural) }\end{array}$ & $\begin{array}{l}\text { two specific } \\
\text { affixes are } \\
\text { available } \\
\text { (class 2) }\end{array}$ \\
\hline $\begin{array}{l}\text { a higher-ranked } \\
\text { constraint blocks } \\
\text { the existing affix } \\
\text { (class 1, class 4) }\end{array}$ & $\begin{array}{l}\text { an even higher- } \\
\text { ranked constraint } \\
\text { forces the existing } \\
\text { affix to appear } \\
\text { (class 2) }\end{array}$ & & $\begin{array}{l}\text { only one specific } \\
\text { genitive affix is } \\
\text { available (class 3) }\end{array}$ \\
\hline
\end{tabular}

In the evaluations shown in (14), the constraint SPEC was irrelevant. That SPEC is necessary can be shown with examples from the plural.

(16) Selection of optimal forms in an accusative plural context

a. Inanimate class 2 nouns ( a] )

\begin{tabular}{|c|c|c|c|c|}
\hline & SPEC , & $\begin{array}{l}\operatorname{MAX}(+\mathrm{hr}) / \\
-\mathrm{pl}, \mathrm{a}]\end{array}$ & $\begin{array}{l}*(+\mathrm{hr}) / V \\
\text {-anim }\end{array}$ & MAX $(+h r)$ \\
\hline kart-y & I & 1 & & $*$ \\
\hline kart-ov & $* !$ & $\begin{array}{l}T \\
1\end{array}$ & * & \\
\hline kart & 1 & 1 & $* !$ & \\
\hline
\end{tabular}


b. Animate class 2 nouns ( a] )

\begin{tabular}{|c|c|c|c|c|}
\hline & SPEC & $\begin{array}{c}\text { MAX }(+h r) / \\
-p l, a]\end{array}$ & $\begin{array}{c}*(+\mathrm{hr}) / V \\
\text {-anim }\end{array}$ & $\operatorname{MAX}(+h r)$ \\
\hline belk-i & te & & & *! \\
\hline belk-ov & *! & & & \\
\hline belok & t & & & \\
\hline
\end{tabular}

The tableau in (16-b) illustrates that the competing form belkov is ruled out because no selectional condition is associated with /-ov/, in comparison to the condition $\mathrm{C}]$, which has a specific selectional requirement that is met and hence is more specific.

This example also demonstrates that lexical underspecification (in this case, of the selectional information associated with an affix) leads to some overgeneration of inflected forms, and therefore forces the existence of constraints such as SPEC which block the ungrammatical forms. From the perspective of lexical economy, additional selectional information is undesirable, and should therefore be reduced. This is the motivation behind the notion of a default affix. However, additional constraints that replace possible lexical information should be as general as possible, and be motivated by independent reasons. This is indeed the case for SPEC, which plays a role in all cognitive domains.

Recall that Russian has three suffixes that serve to derive all accusative and genitive singular forms of nouns: /-u/ is specified for accusative, /-y/ is specified for genitive, and /-a/ is unspecified. Each is associated with different selectional conditions. Is it possible to determine a default suffix in this class? The best candidate would be /-a/, but then the question arises of how /-a/ can be blocked for the inflection classes 2 and 3. Note that /-a/ when applied to an a-ending noun is subject to the Obligatory Contour Principle, which motivates an Avoid constraint such as *(-a)/ a] ("Avoid the ending /-a/ with nouns ending in $-a$."). Likewise, a C-ending noun is not a good candidate for marking a case by $\mathrm{C}$ ], which then motivates an Avoid constraint such as *(C])/ C] ("Avoid the condition that the noun ends in C with nouns ending in C"). If both of these constraints are generalized for palatalized contexts, one arrives at constraints whose contexts are complementary to the respective selectional conditions. Therefore, (17-a) and (17-b) are quite good candidates for Avoid constraints. Less motivated are Avoid constraints such as those in (17-c) and (17-d), especially (17-d) with a negatively specified domain. 
(17) Complementarity of selectional conditions and the contexts of Avoid constraints

\begin{tabular}{|l|c|c|c|c|c|}
\hline & & Exponent & $\begin{array}{c}\text { Lexical } \\
\text { information }\end{array}$ & $\begin{array}{c}\text { Selectional } \\
\text { condition }\end{array}$ & $\begin{array}{c}\text { Avoid } \\
\text { constraint }\end{array}$ \\
\hline a. & A/G.sg & $/$-a/ & $+\mathrm{hr}$ & $/ \mathrm{C}] \vee \mathrm{o}]$ & $*(-\mathrm{a}) / \mathrm{a}] \vee \mathrm{PAL}]$ \\
\hline b. & A/G.pl & $\mathrm{C}]$ & $+\mathrm{pl},+\mathrm{hr}$ & $/ \mathrm{a}] \vee \mathrm{o}]$ & $*(\mathrm{C}]) / \mathrm{C}] \vee$ PAL] \\
\hline c. & G.sg & $/$-y/ & $(+\mathrm{hr})_{N}$ & $/$ a] $\vee$ PAL] & $*(-\mathrm{y}) / \mathrm{C}] \vee \mathrm{o}]$ \\
\hline d. & A.sg & $/$-u/ & $(+\mathrm{hr})_{V}$ & $/ \mathrm{a}]$ & $*(-\mathrm{u}) /$ non a $]$ \\
\hline
\end{tabular}

From the perspective of economy, there is no difference between a disjunctive context of an Avoid constraint and a disjunctive selectional condition associated with the lexical entry. In contrast, for the suffix /-u/ a selectional condition is more economical. From the perspective of a language learner, however, positive instances are favored; he or she will be more likely to detect affix-specific selectional conditions than language-specific Avoid constraints, beside such obvious constraints as *(-a)/ a] and *(C])/ C]. I have no definite opinion regarding the question of how much information is stored in the lexical entries and how much belongs to the constraints. In general, I would prefer a solution that relieves the constraint component of idiosyncratic languagespecific constraints.

The suffix /-u/ also gives rise to the language-specific constraint $\operatorname{MAX}(+\mathrm{hr}) /-\mathrm{pl}$, a]. In a purely generative account the $-u$ accusative rule can easily be formulated, but in such an account the animacy split remains mysterious. Apart from a few exceptions, inanimate nouns choose the nominative form when accusative is required, while animate nouns choose the genitive form in this context. In theory, it could be just the other way around. Once one incorporates the animacy split into the analysis by means of a general markedness constraint, it is the exception that becomes problematic. The question, then, is not why syncretism arises, but why it is resolved in some instances but not others. Therefore, one has to deal with the fact that there is one accusative suffix (namely /-u/) that is possible with inanimate nouns. From the generative perspective, this affix gets preference because it is more specific. From the constraint perspective, one has to deal with the question of what makes class 2 nouns so special that they can override the general constraint. I have no ready explanation of why the suffix /-u/ exists in Russian nouns. The best suggestion I can give is that gender distinctions made in the nominative should also be visible in the accusative. The language-specific 
constraint $\operatorname{MAX}(+\mathrm{hr}) /-\mathrm{pl}$, a] would then reflect a more general constraint of paradigmatic distinctivity (or expressiveness). In any case, the problem of the $-u$ accusative rule is a minor problem compared with the mystery imposed by the direction of the animacy split.

There may be alternative explanations of the Russian nominal forms chosen in accusative contexts. The point I have tried to make is that any sort of rules of referral are unnecessary. In my account it is the interaction of categorial information, lexical representation, and a few constraints that serves the purpose in question.

This account could be extended to some minor classes of Russian nouns in which D.sg/G.sg syncretism is observed (marked by /-i/); these nouns either have /-u/ in the accusative (linija ('line')) or are subject to A/N syncretism (čast' ('part')). Note that dative $[+\mathrm{hr},+\mathrm{lr}]$ and genitive $[+\mathrm{hr}]_{N}$ form a natural class characterized by [+hr], which also includes accusative; therefore, a D/G syncretism can arise only if the forms that occupy accusative contexts are determined by independent means (such as the suffix /- $\mathrm{u} /$ or the constraint $*(+\mathrm{hr})_{V}$ /inanim). There are also instances of dative-locative syncretism: in class 2 nouns (kárt-e ('to/in the map')), as well as in the above mentioned classes with $\mathrm{D} / \mathrm{G}$ syncretism. This indicates that the Russian locative is also based on the feature [+hr], with an additional semantic feature. Recall that kárt- $u$ is specified as $[+\mathrm{hr}]_{V}$ and kárt-y as [+hr $]_{N}$; this leaves space for kárt-e being specified simply as [+hr] (dative or locative). In contrast, no syncretism appears with the instrumental, which should be considered a purely semantic case in Russian. Altogether, these facts strongly indicate an underspecification analysis of syncretism.

\section{The G.Sg/N.PI Syncretism in Indo-European}

Within the Indo-European family, many instances of syncretism between G.sg and N.pl can be found. This kind of homonymy is, however, quite rare outside of Indo-European. Tables (18) to (20) illustrate the syncretism with examples from Latin, Greek, and Russian. 
(18) Syncretism of G.sg and N.pl in Latin

\begin{tabular}{|l|c|c|c|}
\hline & $\begin{array}{c}\text { o-declension } \\
\text { 'wall' masc. }\end{array}$ & $\begin{array}{c}\text { a-declension } \\
\text { 'flame' fem. }\end{array}$ & $\begin{array}{c}\text { u:-declension } \\
\text { 'fruit' masc. }\end{array}$ \\
\hline N.sg & mu:r-us & flamma & fru:ct-us \\
\hline G.sg & mu:r-i: & flamm-ae & fru:ct-u:s \\
\hline N.pl & mu:r-i: & flamm-ae & fru:ct-u:s \\
\hline
\end{tabular}

(19) Syncretism of G.sg and N.pl in the Attic declension of Classical Greek

\begin{tabular}{|l|c|c|}
\hline & 'temple' & 'gracious' \\
\hline N.sg & neó:-s & íleo:-s \\
\hline G.sg & neó: & íleo: \\
\hline N.pl & neó: & íleo: \\
\hline
\end{tabular}

(20) Syncretism of G.sg and N.pl in Russian

\begin{tabular}{|l|c|c|c|c|}
\hline & $\begin{array}{c}\text { class 1 } \\
\text { 'factory' masc. }\end{array}$ & $\begin{array}{c}\text { class 4 } \\
\text { 'swamp' neuter }\end{array}$ & $\begin{array}{c}\text { class 2 } \\
\text { 'map' fem. }\end{array}$ & $\begin{array}{c}\text { class 3 } \\
\text { 'notebook' fem. }\end{array}$ \\
\hline N.sg & zavód & bolót-o & kárt-a & tetrád' \\
\hline G.sg & zavód-a & bolót-a & kárt-y & tetrád-i \\
\hline \multicolumn{5}{|c}{} \\
\hline N.pl & zavód-y & bolót-a & kárt-y & tetrád-i \\
\hline
\end{tabular}

For Stump (2001), all these instances exhibit directional syncretism, represented by rules of referral. In the Russian case, which he discusses in detail, he assumes bidirectional syncretism, illustrated in (20). The two directions of referral can be detected if one looks at the masculines in class 1, where G.sg and N.pl have different exponents:

\section{(21) Class 1 suffixes}

a. $/-\mathrm{a} /,(+\mathrm{hr})_{N}$

b. $/-\mathrm{y} /,+\mathrm{pl}$

Obviously, the first suffix can be generalized to class 4 genitives, and the second suffix can be generalized to all non-neuter plurals. More specifically, class 4 neuter nouns share the G.sg ending with the masculines, but in addition have the ending /-a/ in N.pl. Therefore, Stump argues, their N.pl should be considered as patterning after G.sg; that is, there should be a rule of referral G.sg $\rightarrow \mathrm{N}$.pl for class 4 neuter nouns. Likewise, class 2 and class 3 nouns share the N.pl with class 1 masculines and have the same ending in the 
G.sg. In this case, then, a rule of referral with the opposite direction should be assumed, that is, N.pl $\rightarrow$ G.sg.

Consequently, the language learner who has to detect the proper generalizations about the Russian nominal paradigm not only has to find out the syncretism, but also needs evidence for the direction of referral. In other words, the Russian-learning child first has to detect the class 1 masculine suffixes in (21) in order to be able to make the respective generalizations for the neuters of class 4, as well as for class 2 and class 3 nouns. Because of such cognitively unmotivated dependencies, I doubt whether rules of referral have any psycholinguistic reality. One could think of other interpretations for those rules of referral, for instance, that they capture diachronic generalizations, but no such claim is made by Stump.

Stump's bidirectional analysis for the G.sg/N.pl syncretism in Russian is confronted with further problems. First, n-stems in Russian display a distribution of $/-\mathrm{a} /$ and $/-\mathrm{y} /$ which is the reverse of that of class 1 masculine nouns, as shown in (22-a). Therefore, one could also argue for another direction in the rules of referral. Moreover, the exponent of N.pl of neuter nouns is /-a/ in several Indo-European languages, which is shown in (22-b) for Greek and in (23) for Latin. Therefore, from a diachronic perspective it is highly unmotivated to consider G.sg $\rightarrow$ N.Pl to be the rule of referral for neuter nouns in Russian. In any case, neuter nouns usually do not participate in the G.sg/N.pl syncretism, unless G.sg ends in /-a/ for independent reasons.

(22) G.sg and N.pl of neuter nouns in Russian and Greek

\begin{tabular}{|l|c|c|c|}
\hline & a. Russian & \multicolumn{2}{|c|}{ b. Greek } \\
\hline & $\begin{array}{c}\text { n-stems } \\
\text { 'name' }\end{array}$ & $\begin{array}{c}\text { o-declension } \\
\text { 'gift' }\end{array}$ & $\begin{array}{c}\text { consonantal stems } \\
\text { 'body' }\end{array}$ \\
\hline N.sg & ímja & do:r-on & so:ma \\
\hline G.sg & ímen-i & do:r-ou & so:mat-os \\
\hline N.pl & imen-á & do:r-a & so:mat-a \\
\hline
\end{tabular}

(23) G.sg and N.pl of neuter nouns in Latin

\begin{tabular}{|l|c|c|c|}
\hline & $\begin{array}{c}\text { o-declension } \\
\text { 'gift' }\end{array}$ & $\begin{array}{c}\text { u-declension } \\
\text { 'horn' }\end{array}$ & $\begin{array}{c}\text { consonantal stems } \\
\text { 'gender' }\end{array}$ \\
\hline N.sg & do:n-um & cornu & genus \\
\hline G.sg & do:n-i & cornu:-s & gener-is \\
\hline N.pl & do:n-a & cornu-a & gener-a \\
\hline
\end{tabular}


A less strong view of the observed syncretism is simply to accept that both /-a/ and /-y/ are homonymous suffixes.

(24) Affixes that show G.sg/N.pl syncretism

a. $/-\mathrm{a} /,<(+\mathrm{hr})_{N} \vee+\mathrm{pl}>$ with neuter nouns ending in /-o/ (class 4)

b. /-y/, $<(+\mathrm{hr})_{N} \vee+\mathrm{pl}>$ with nouns ending in /-a/ or PAL (class $2 \&$ class 3$)$

c. General format: $\left\langle(+\mathrm{hr})_{N} \vee+\mathrm{pl}>\right.$

We may ask why such an ambiguity in the set of affixes exists. First, these affixes mark just one dimension, either that of case or that of number, but not both. The contexts in which these forms occur are largely complementary, so that the context easily can resolve the ambiguity. Moreover, it seems to be economical for a language to employ only a small set of affixes, even at the price of ambiguity. Note that /-z/ serves several inflectional functions in English (dog-s, he play-s); similarly, /-s/, /-n/, and /-t/ are all polyfunctional in German. Second, the observed syncretism permits analogy by means of crossparadigmatic uniformity, and at the same time some variance in the distribution of affixes, that is, efficient distinction of inflectional classes. New lexical items can be patterned according to other existing and productive classes.

Based on the observation that the G.sg/N.pl syncretism is found again and again in many Indo-European languages, while it is quite rarely attested in other language families, one can assume that Proto-Indo-European already had this kind of syncretism in productive nominal inflection. In fact, historical linguists consider -os/-o:s to be the exponents of G.sg/ N.pl with IndoEuropean masculine or feminine o-stems (and $-s$ with some other classes of nouns). ${ }^{11}$ Such an accidental syncretism, caused by reasons other than underspecification, can be captured by the meta-generalization that allows affixes to have the information $<(+\mathrm{hr})_{N} \vee+\mathrm{pl}>$. More precisely, a meta-generalization of this kind should be considered to be an identity constraint on possible affix information, which, however, happens to be violated in the neuter nouns of Indo-European, as well as in the masculines of class 1 Russian nouns.

\footnotetext{
${ }^{11}$ The o-stems also have -os in the N.sg. According to Beekes $(1995,193 f),$.$-s was a former$ ergative marker, which was not distinguished from the genitive. This affix remained after the nominal system had shifted to an accusative-based system.
} 
(25) $\operatorname{IDENT}\left((+\mathrm{hr})_{N},+\mathrm{pl}\right)$ :

Exponents of genitive and plural are identical. ${ }^{12}$

Analogy is not restricted to the actual forms of affixes; it can also be triggered by the grammatical function of affixes. As already mentioned, all $2 \mathrm{sg}$ and $1 \mathrm{pl}$ inflected verbs of Hua have identical forms, regardless of how they are spelled out in the respective mood, a fact that can be captured by the constraint IDENT([+2], $[+1,+\mathrm{pl}])$. Recall that Stump (2001), too, accepts a metageneralization in this case, which he subsumes under the type of symmetrical syncretism.

My proposal, then, is to subsume many more instances that have been claimed to exhibit directional syncretism under the type of symmetrical syncretism. There is no need for the stronger device of directional syncretism; on the contrary, the required rules of referral are confronted with serious learning problems. It is therefore not necessary to investigate in detail whether in the Latin examples given above in (23) G.sg patterns after N.pl or the other way around. In Latin, the constraint $\operatorname{IDENT}\left((+\mathrm{hr})_{N},+\mathrm{pl}\right)$ is rather strong; it is violated only by neuter nouns (ending in $-a$ in N.pl), as well as by nouns belonging to the consonantal inflection (where, however, G.sg and N.pl share the final /-s/). Without going into details, I would suggest that $* \operatorname{IDENT}\left((+\mathrm{hr})_{N},+\mathrm{pl}\right) /$ neuter ranks above $\operatorname{IDENT}\left((+\mathrm{hr})_{N},+\mathrm{pl}\right)$, so that separate suffixes can appear with neuter nouns. If, however, the inflected forms of items in a small and unproductive class are already listed in the lexicon, they are no longer subject to any of the inflectional constraints. This could have happened in the consonantal inflection of Latin.

A language learner probably first acquires full inflected forms. He/she will then try to generalize by searching for affixes that are specific to a word class characterized by phonological features and/or gender (as detected through agreement patterns). It is not clear whether the language learner also detects cross-paradigmatic regularities, such as the above-mentioned ones, and whether all language learners do so. Only if a language learner performs this step, which probably will be rather late in the acquisition process, will he construct a constraint ranking that puts certain affix information before others. Thus, the constraints at work here are language-specific.

On the basis of examples from Icelandic, Wurzel (1987) suggested that paradigms can be best characterized by a set of paradigm structure condi-

\footnotetext{
${ }^{12}$ This identity constraint belongs to the family of Output-Output constraints. If the exponents are identical, then, of course, the inflected forms are identical, too.
} 
tions, ordered from more general ones to class-specific ones. By their very nature, most of these conditions are highly language-specific, and it is doubtful whether a language learner will ever acquire them. By contrast, the markedness constraints discussed in section 2 and 3 are based on universally given scales. What is language-specific there is whether a gender such as neuter is established and at which point the faithfulness constraint Max(+hr) intervenes. In any case, a language learner will acquire an "unstipulated" syncretism based on a natural class and harmonic alignment probably earlier than a "symmetrical" syncretism in which two independent dimensions share the same exponent accidentally.

Note in this connection that German constitutes another case where two marked dimensions share the same exponents. The feminine and plural article forms die and der are identical (except for dative plural with the form den), and all strong nominal elements that agree with the noun share the same endings (ein-e klug-e Frau ('a wise woman'), einig-e klug-e Männer ('some wise men')). Under the assumption that German gender is neutralized in the plural, one can consider feminine and plural to be independent dimensions, so that the syncretism at issue represents just another case of meta-generalization, namely, IDENT $(+\mathrm{f},+\mathrm{pl})$.

\section{Summary}

In this paper I have tried to do justice to the concept of directional syncretism. Treating syncretism as induced by a function on paradigm cells makes the strongest claim. However, if a child is assumed to acquire such a kind of syncretism, he or she has to know the content of the syncretism when only halfway through. Why should someone who is learning the language go any further in the process of generalization?

The typology of syncretism proposed by Stump is not a real typology, because it is not guided by features of grammar but rather by features of analyzability. If one type of syncretism is characterized by a rule of grammar and another type by a meta-generalization outside grammar, the typology comprises nonparallel categories. Therefore, I reanalyze these meta-generalizations as identity conditions on inflectional elements, thereby contributing to economy.

Furthermore, I have extended the class of morphological objects that give rise to syncretism via lexical underspecification. It not only includes the wellknown natural classes, such as those based on gender (e.g., non-feminine 
comprising masculine and neuter), but also classes of morphological case. In the theory outlined in Wunderlich (1997), accusative is a marked case with respect to nominative, and accusative-genitive form a natural class. Therefore, the syncretisms observed with the Russian accusative, which apparently constitute one of the most compelling pieces of evidence in favor of a directional account, can just as well be analyzed by means of lexical underspecification. Such an account is feasible if a general constraint is assumed that regulates the animacy split.

As a result, all syncretism should be regarded as a matter of lexical information, supplemented by a set of constraints that determine the choice between inflected forms. Stump's typology is reduced to his third and fourth types, so-called unstipulated and symmetrical syncretism. In the unstipulated type we find genuine lexical underspecification (no disjunctions), while in the symmetrical type we find disjunctions that may be forced only by identity constraints. The problem with these constraints (or meta-generalizations, according to Stump) is that they are language-specific. A constraint that forbids the expression of accusative in inanimate nouns, and similarly a constraint that forbids the expression of accusative in neuter nouns, is well-motivated by universal tendencies. However, a constraint that requires N.pl and G.sg to be identically realized certainly is not universal. Nevertheless, both Stump and I are convinced that there exist quite systematic syncretisms that can be handled only by such a device. The concept of lexical economy makes it at least plausible that independent grammatical features (such as plural and genitive, feminine and plural, $1 \mathrm{sg}$ and $2 \mathrm{pl}$ ) may share their exponents.

Needless to say, there is much more evidence for the existence of language-specific constraints, which come into being only as a result of the individual history of languages (or language families) and are transmitted to subsequent generations by the combined forces of imitation and analogy.

\section{References}

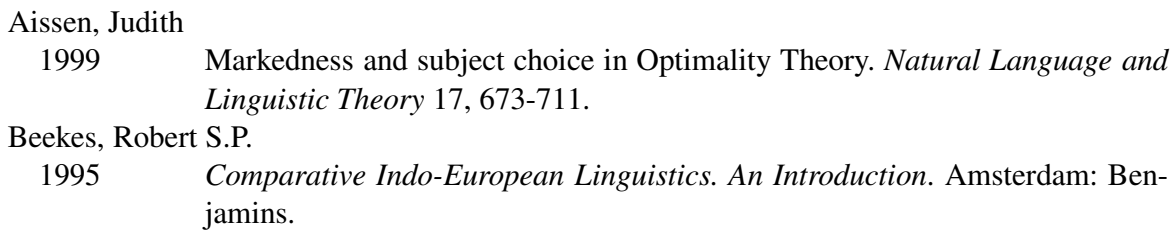


Brown, Dunstan P. \& Andrew R. Hippisley

1994 Conflict in Russian Genitive Plural Assignment: A Solution Represented in DATR. Journal of Slavic Linguistics 2, 48-76.

Corbett, Greville G.

1982 Gender in Russian: An Account of Gender Specification and Its Relationship to Declension. Russian Linguistics 6, 197-232.

1991 Gender. Cambridge: Cambridge University Press.

Evans, Nicholas, Dunstan Brown, \& Greville Corbett

2001 Polysemy in the Dalabon Pronominal Prefix Paradigm: A Referral-Based Treatment. In Geert Booij \& Jaap van Marle (eds.), Yearbook of Morphology 2000, 187-231. Dordrecht: Kluwer.

Haiman, John

1980 Hua: A Papuan Language of the Eastern Highlands of New Guinea. Amsterdam: Benjamins.

Müller, Gereon

2002 Remarks on Nominal Inflection in German. In Ingrid Kaufmann \& Barbara Stiebels (eds.), More than Words. A Festschrift for Dieter Wunderlich, 113145. Berlin: Akademie Verlag.

Schmitt-Brandt, Robert

$1998 \quad$ Einführung in die Indogermanistik. Tübingen: Francke.

Stiebels, Barbara

$2000 \quad$ Linker Inventories, Linking Splits and Lexical Economy. In Barbara Stiebels \& Dieter Wunderlich (eds.), Lexicon in Focus, 211-245. Berlin: Akademie Verlag.

2002 Typologie des Argumentlinkings: Ökonomie und Expressivität. Berlin: Akademie Verlag.

Stump, Gregory

1993 On Rules of Referral. Language 69, 449-479.

2001 Inflectional Morphology. A Theory of Paradigm Structure. Cambridge: Cambridge University Press.

Wunderlich, Dieter

1996 Minimalist Morphology: The Role of Paradigms. In Geert Booij \& Jaap van Marle (eds.), Yearbook of Morphology 1995, 93-114. Dordrecht: Kluwer.

1997 Cause and the Structure of Verbs. Linguistic Inquiry 28, 27-68.

2001 A Correspondence-Theoretic Analysis of Dalabon Transitive Paradigms. In Geert Booij \& Jaap van Marle (eds.), Yearbook of Morphology 2000, 233-252. Dordrecht: Kluwer.

Wunderlich, Dieter \& Ray Fabri

1995 Minimalist Morphology: An Approach to Inflection. Zeitschrift für Sprachwissenschaft 14, 236-294.

Wurzel, Wolfgang Ullrich

1987 Paradigmenstrukturbedingungen: Aufbau und Veränderung von Flexionsparadigmen. In A. G. Ramat (ed.), Papers from the 7th International Conference on Historical Linguistics, 629-644. Amsterdam: Benjamins. 